CLINICAL PRACTICE

Clinical Images

\section{DNR Tattoos: A Cautionary Tale}

\author{
Lori Cooper, MD and Paul Aronowitz, MD
}

California Pacific Medical Center, San Francisco, CA, USA.

J Gen Intern Med 27(10):1383

DOI: $10.1007 / \mathrm{s} 11606-012-2059-8$

(c) Society of General Internal Medicine 2012

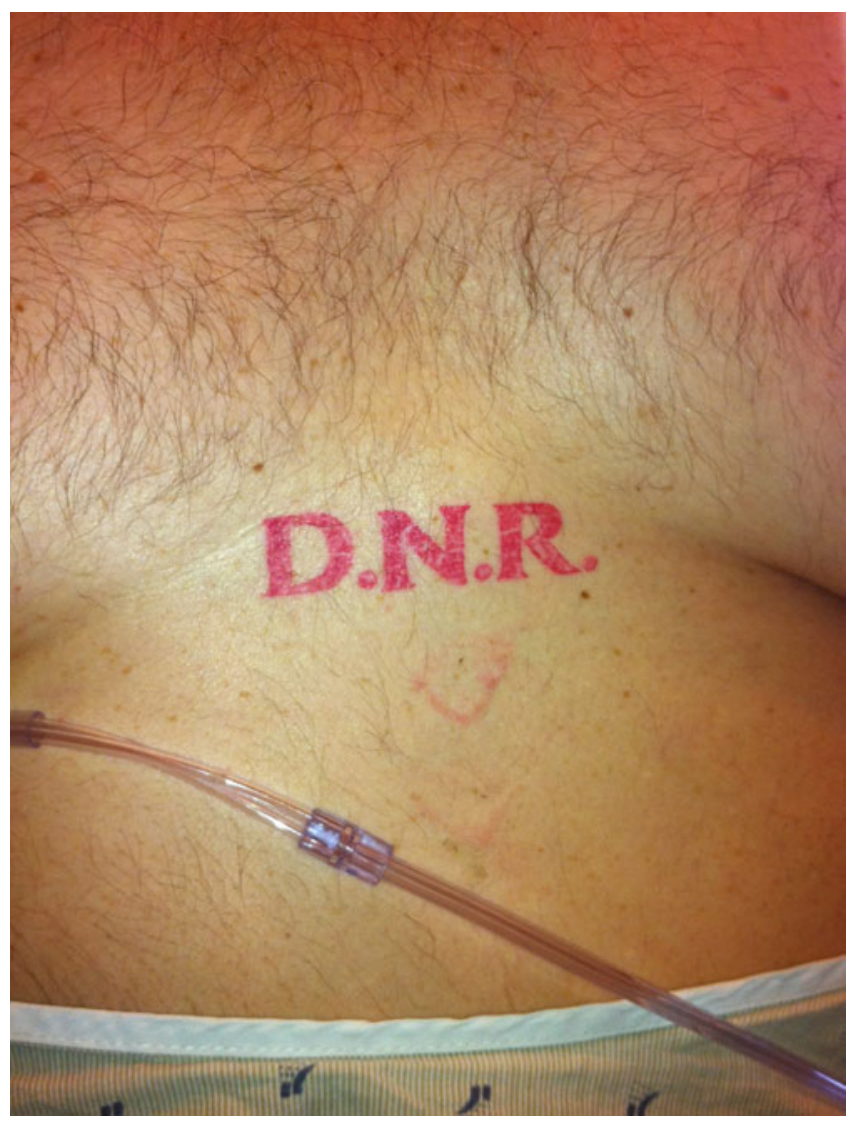

Figure 1. Patient's "D.N.R." tattoo.

\begin{abstract}
A 59-year-old man with diabetes mellitus, peripheral A vascular disease, hypertension and dyslipidemia was admitted to the hospital for a below-the-knee amputation due to chronic non-healing wounds of his lower extremity. Physical examination revealed a "D.N.R." tattoo on his chest (Fig. 1). Upon reviewing his code status, he indicated that he would want resuscitative efforts initiated in the event of a cardiac or respiratory arrest. However, he did not want prolonged attempts at resuscitation. When asked why his tattoo conflicted with his wishes to be resuscitated, he explained that he had lost a bet playing poker with fellow ancillary hospital staffers while inebriated in his younger years; the loser had to tattoo "D.N.R." across his chest. His code status was subsequently documented correctly in his medical record with further explanation of his wishes. Despite his comorbidities, he was relatively active in his outside life and was medically stable during his time in the hospital. It was suggested that he consider tattoo removal to circumvent future confusion about his code status. He stated he did not think anyone would take his tattoo seriously and declined tattoo removal.
\end{abstract}

Corresponding Author: Lori Cooper, MD; California Pacific Medical Center, 2351 Clay St. Suite 380, San Francisco, CA 94115, USA (e-mail: Lacoops@hotmail.com).

Received October 10, 2011

Revised March 5, 2012

Accepted March 20, 2012

Published online May 2, 2012 